\title{
Long non-coding RNA CRNDE may be associated with poor prognosis by promoting proliferation and inhibiting apoptosis of cervical cancer cells through targeting PI3K/AKT
}

\author{
H. Y. YANG, C. P. HUANG*, M. M. CAO, Y. F. WANG, Y. LIU \\ Gynecological Clinic, Second Hospital of Shandong University, Jinan, Shandong, China \\ *Correspondence: cuipinghuang3102@sina.com
}

Received December 25, 2017 / Accepted March 15, 2018

\begin{abstract}
Long non-coding RNAs (lncRNAs) are attracting more and more attention from researchers because they are relatively new factors in regulating biological processes in human cancers. The Colorectal Neoplasia Differentially Expressed (CRNDE) lncRNA is transcribed from chromosome 16 on the opposite strand to the neighboring IRX5 gene. It was originally discovered abnormally expressed in colorectal cancer (CRC) and was certified a critical biomarker in many cancers. However, its biological function and mechanism underlying the tumorigenesis of cervical cancer still require exploration. This study confirmed that CRNDE is markedly up-regulated in clinical tissues and cell lines of cervical cancer. The high expression of CRNDE positively correlates with advanced FIGO stage and lymph node metastasis. Furthermore, the overall survival rate in the group with highly expressed CRNDE was worse, and the high level of CRNDE may be regarded a prognostic factor because of its results from proportional hazard analysis. Loss-of-function assays revealed that CRNDE influences proliferation and apoptosis in cervical cancer cells, and Western blot assays revealed that the PI3K/AKT pathway was inactivated in response to CRNDE knockdown. Therefore, we conclude that CRNDE exerts oncogenic function in cervical cancer and should be further explored as a novel prognostic predictor.
\end{abstract}

Key words: IncRNA CRNDE, cervical cancer, proliferation, PI3K/AKT

Cervical cancer (CC) has been one of the most common global gynecological malignancies for several decades. Despite novel therapies and vaccination against humanpapilloma virus HPV in younger women, the survival rate of cervical cancer patients is still dismal. Therefore, it is necessary to find novel therapeutic methods for CC patients and it is crucial to find potential therapeutic targets and establish the molecular mechanisms modulating CC progression.

Long noncoding RNAs (lncRNAs) are a group of RNA molecules longer than $200 \mathrm{t}$ which have been verified as extremely significant in tumorigenesis [1-8]. The long non-coding RNA Colorectal Neoplasia Differentially Expressed (CRNDE) transcribed from chromosome 16 on the opposite strand to the neighboring IRX5 gene is the most up-regulated lncRNA in colorectal cancer [9]. It was originally identified to be aberrantly expressed in CRC [10] and other types of cancers, including HCC, ovarian, gallbladder and kidney cancers and glioma [11-16]. Although CRNDE has been a research focus in many types of cancers, its specific function in cervical cancer has not yet been fully elucidated. It has been proven capable of promoting proliferation, metastasis, EMT progress and impedes apoptosis in all the above cancers. Additionally, high expression of CRNDE usually predicts poor prognosis. Many documents have reported that CRNDE is oncogenic, and based on the associated research, we studied the biological role of CRNDE in CC. It is speculated that the oncogenic functions of CRNDE are exerted in cancers so we examined the effects of CRNDE on CC biological activity.

The PI3K/AKT signaling pathway was proven important in the proliferation and metastasis of cancer cells [17]. Our literature research revealed that this is a classic pathway and significant for cancer research because it can promote progression and development of tumors. Once this signaling pathway was activated, the cancer cells would powerfully generate. The PI3K-AKT pathway function has been verified in many cancers, such as gallbladder carcinoma [15], gastric cancer [18] and thyroid cancer [19]. In this study, we tested the expression level of CRNDE in clinical tissues and cell lines by quantitative real-time PCR (qRT-PCR) The relation- 
ship between CRNDE deregulation and clinical characteristics or prognosis was analyzed and functional assays indicated that silenced CRNDE weakened CC cell proliferation and prompted cell apoptosis. Mechanism experiments finally revealed that PI3K/AKT is related to CRNDEmediated function in cervical cancer and findings revealed that CRNDE provides novel insights for exploring clinical treatment targets.

\section{Materials and methods}

The prognostic information and expression pattern of CRNDE in cervical cancer patients were downloaded from the TCGA database and analyzed by edger function.

Clinical samples. A total of 63 pairs of cervical cancer tissue samples and matched adjacent normal tissue samples were selected from patients who received surgery from 2008 to 2012 in the Gynecology, Second Hospital of Shandong University. No patients recruited in this study had received chemotherapy or radiotherapy. This study acquired approval of the Research Ethics Committee of the Second Hospital of Shandong University and all patients provided informed consent. All specimens were handled and made anonymous in accordance with the ethical and legal standards.

Cell culture and transfection. CC cells (C33A, CaSki, $\mathrm{SiHa}$, and $\mathrm{HeLa}$ ) and the normal human cervical epithelial cell line (H8) were obtained from the Type Culture Collection of the Chinese Academy of Sciences (Shanghai Institute of Biochemistry and Cell Biology, Shanghai, China). From these cells, HeLa and CaSki cell lines were maintained and cultured in RPMI 1640 medium (Gibco, Thermo Scientific, Waltham, MA) containing $10 \%$ of fetal bovine serum (FBS; Gibco). In addition, $\mathrm{SiHa}, \mathrm{C} 33 \mathrm{~A}$ and $\mathrm{H} 8$ cells were preserved in Dulbecco's modified Eagle medium (Gibco) supplemented with $10 \%$ of FBS. All cells were maintained in a cell incubator with a humidified atmosphere (37 $\mathrm{C}$ and $5 \% \mathrm{CO}_{2}$ ).

To knock down CRNDE expression, siRNA specifically targeted CRNDE and the negative control siRNA (si-NC) were constructed by GenePharma Co. (Shanghai, China). The siRNA sequence is 5' UAUGGAAGCAUCACACUUAACACCU 3'; 5' GCUAUUGGAAGGAGGAGAUUCUGAA 3. For colony formation assay, cells were transfected with CRNDE specific shRNA, sh-CRNDE and negative controls were bought from GenePharma Co. (Shanghai, China). The sequence of CRNDE was then sub-cloned into the pcDNA 3.1 vector and PcDNA-CRNDE accompanied with Lipofectamine 2000 (Invitrogen, Carlsbad, CA, USA) was used to over-express CRNDE in CC cells. Empty pcDNA vector was used as negative control (NC).

Quantitative real-time PCR (qRT-PCR). TRIzol reagent (Invitrogen) was isolated total RNA from CC specimens and cell lines. The PrimeScript RT reagent Kit (Takara Bio Company, Shiga, Japan) was then applied to synthesize the cDNA from $200 \mathrm{ng}$ of previously extracted total RNA. The SYBR Green Kit (Takara Bio Company), cDNA was ampli- fied by qRT-PCR in an ABI PRISM 7500 Sequence Detection System (Applied Biosystems). GAPDH was used as an internal control. In order to determine the relative quantification of gene expression levels, the $2^{-\Delta \Delta \mathrm{Ct}}$ method was utilized. The sequences of all premiers were synthesized by RiboBio (Guangzhou, China) as shown in following: CRNDE, forward 5'-TGAAGGAAGGAAGTGGTGCA-3' and reverse 5'-TCCAGTGGCATCCTACAAGA-3'; GAPDH, forward 5'-TGCACCACCAACTGCTTAG-3' and reverse 5'-AGTAGAGGCAGGGATGATGTTC-3'. Each experiment was performed in triplicate.

Cell cytoplasm/nucleus fraction isolation. To extract cytoplasmic and nuclear fractions from CC cells, NE-PER Nuclear and Cytoplasmic Extraction Reagents (Thermo Scientific, Waltham, MA, USA) were employed. Then, qRTPCR analysis was designed to examine the levels of lncRNA CRNDE in the nucleus and cytoplasm. U6 and GAPDH were used as positive and negative controls, separately.

MTT assay. Cells $\left(3 \times 10^{3} \sim 6 \times 10^{3}\right)$ were inoculated in a plate with 96 wells ( $200 \mu \mathrm{l}$ per well, 6 repeated wells) at $37^{\circ} \mathrm{C}$ and $5 \% \mathrm{CO}_{2}$ for one to three days. MTT solutions $(20 \mu$ l, density: $5 \mathrm{mg} / \mathrm{ml}$, Sigma) was gradually added to each well. After incubation for $4 \mathrm{~h}$ at $37^{\circ} \mathrm{C}$ and $5 \% \mathrm{CO}_{2}$, this was stopped, and the culture medium was abandoned. DMSO (150 $\mu$ l) (Sigma) added to each well and gently shaken for $10 \mathrm{~min}$ to promote the dissolution of crystallization. Absorbance values (OD) were measured by enzyme-linked immunosorbent detector at different time points $(12 \mathrm{~h}, 24 \mathrm{~h}, 48 \mathrm{~h}, 72 \mathrm{~h}, 96 \mathrm{~h})$. The experiment was in triplicate.

CCK-8 assay. CC cells (CasKi and HeLa) were transferred into the 96-well plates at 12 hour's post-transfection. 101 CCK-8 solution (Beyotime, Shanghai, China) was added to each cell at different time point $(24,48$ and 72 hours) and absorbance was measured at $450 \mathrm{~nm}$ after the treated cells were incubated for 4 hours at $37^{\circ} \mathrm{C}$.

Colony formation assay. We plated 500 cells/well in 6-well plates and incubated them in RPMI 1640 containing $10 \% \mathrm{FBS}$ at $37^{\circ} \mathrm{C}$. After two weeks, cells were observed to be fixed and $0.1 \%$ of crystal violet stained these cells. Finally, we counted the number of visible colonies manually.

Flow cytometric analysis of apoptosis. After transfection for 48 hours with the indicated plasmid or negative control, the cells were harvested. Annexin V: FITC Apoptosis Detection Kits (BD Biosciences, USA), and flow cytometry detected the apoptosis rate. All samples were independently assayed in triplicate.

Western blot assay. Cells were lysed with RIPA (Thermo Scientific, USA) supplemented with protease inhibitors (Roche, Switzerland). Proteins (fifty micrograms) were separated by SDS-PAGE, followed by their transfer to PVDF membranes (Roche, Switzerland). The membranes were then blocked and incubated with rabbit anti-human cleaved caspase-3 antibody (1:1,000; 9661, CST, USA), cleaved PARP antibody (1:1,000; 5625, CST, USA), p-PI3K (1:1,000; 4228, CST, USA), PI3k antibody (1:1,000; 4249, CST, USA), 
p-AKT (1:1,000; 4060, CST, USA), AKT antibody (1:1,000; 4685 , CST, USA) at $4^{\circ} \mathrm{C}$ overnight. Membranes were then washed and probed by TBST and HRP Goat-anti-Rabbit (1:2000; sc-2040, Santa Cruz Biotechnology) independently at room temperature for $2 \mathrm{~h}$. Finally, the protein levels were semi-quantitatively assessed by ECL (Thermo Scientific) and normalized to GAPDH $(1: 3,000 ; 5174$, CST, USA).

Statistical analysis. SPSS 19.0 software (SPSS Inc., Chicago, IL, USA) analyzed samples. Data is shown as means \pm standard deviation (SD). The Pearson $\chi^{2}$ test evaluated the relationship between the expression of CRNDE and clinicalpathological factors, and comparison between two groups was by Student " $\mathrm{t}$ " test. Multiple comparisons were made by One-way ANOVA, and Kaplan-Meier survival analysis was performed. Differences among patient groups were compared by log-rank test and factors associated with the overall survival were identified by Cox regression model for multivariate survival analysis of cervical cancer. P-value less than 0.05 indicated statistical significance.

\section{Results}

CRNDE was significantly over-expressed in cervical cancer tissues and cell lines. In order to explore the biological functions of CRNDE in cervical cancer, we firstly examined the expression level of CRNDE in tissues (306 CC tissues and three normal tissues) obtained from the TCGA database (Supplementary Table 1). CRNDE was extremely up-regulated in CC tissues compared to normal tissues. To obtain further evidence, we measured the expression level of CRNDE in both 63 cervical cancer tissues and their corresponding normal tissues. As illustrated in Figure 1A, the level of CRNDE was significantly increased in cervical cancer tissues in comparison with that in the matched adjacent normal tissues.
We then measured the level of CRNDE in CC cell lines ( $\mathrm{SiHa}, \mathrm{CasKi}, \mathrm{HeLa}$ and $\mathrm{C} 33 \mathrm{~A}$ ) and a normal human cervical epithelial cell line (H8). As demonstrated in Figure 1B, compared with the normal human epithelial cell line, CRNDE was obviously up-regulated in cancerous cell lines, especially in the HeLa and CaSki cells which were selected for following experiments. These findings indicated that CRNDE could well be a cervical cancer oncogene.

The correlation between CRNDE level and CC clinicalpathological features. Pearson's $\chi^{2}$ test clarified the relevance between CRNDE expression and clinical-pathological features of cervical cancer patients. Statistical results revealed that high CRNDE level was obviously correlated with FIGO stage $\left({ }^{*} \mathrm{p}=0.045\right)$ and lymph node metastasis $\left({ }^{*} \mathrm{p}<0.001\right)$ rather than with other clinical-pathological factors such as age, tumor size, histology and differentiation (Table $1 ; p>0.05$ ) in terms of cervical cancer patients. These combined findings indicate that high level of CRNDE was closely related with cervical cancer progression. The gynecological oncology was divided into different stages in accordance with the specific pathological features. The standards for stage division were enacted by the International Federation of Gynecology and Obstetrics (FIGO) [20]. According to the specific biological features, patient samples used in this study were divided into stage Ib-IIa and stage IIb IIIa groups.

High level of CRNDE predicted poor prognosis in cervical cancer patients. The mean value of CRNDE expression was taken as the cutoff value between high and low expression. 63 cervical cancer tissues were classified into two groups (Low: $n=31$; High: $n=32$ ) to further justify whether CRNDE expression had internal association with patient survival rate. In addition, the potential value of CRNDE was estimated for relevant clinical and pathological factors. Based on the Cox regression model, multivariate analysis established that high CRNDE level could be an independent
A

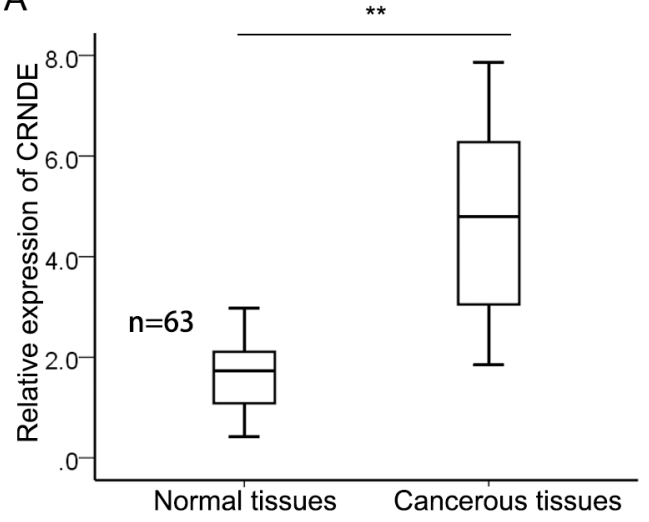

B

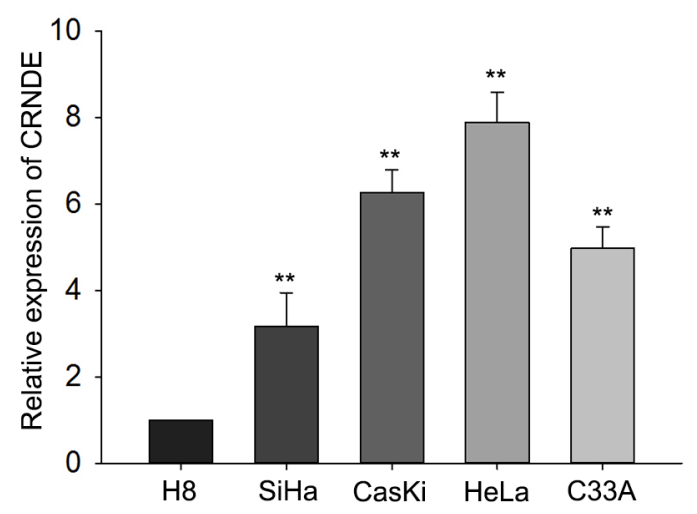

Figure 1. CRNDE was significantly over-expressed in CC tissues and cell lines. The level of CRNDE was clearly detected by qRT-PCR in CC tissues (A) and CC cells (B). Error bars represent means \pm SD from at least three independent experiments were shown. ${ }^{* *} \mathrm{p}<0.01$. 
prognostic factor in CC (Table $\left.2,{ }^{*} \mathrm{p}=0.036,{ }^{* *} \mathrm{p}=0.002\right)$. The result of the Kaplan-Meier analysis suggested that patients from the group with high CRNDE expression had markedly shorter overall survival than the low expression group $(\mathrm{p}<0.01$, Figure 2A). All these results suggested that CRNDE be proposed as a potential biomarker for poor prognosis in cervical cancer. The survival curve downloaded from TCGA database also showed that high expression of CRNDE was positively correlated with the short survival time of CC patients ( $p=0.00206$, Figure 2B).

Table 1. Correlation between lncRNA-CRNDE expression and clinical features $(n=63)$.

\begin{tabular}{|c|c|c|c|}
\hline \multirow{2}{*}{ Variable } & \multicolumn{2}{|c|}{ LncRNA-CRNDE Expression } & \multirow{2}{*}{ p-value } \\
\hline & low & high & \\
\hline \multicolumn{4}{|l|}{ Age } \\
\hline$<50$ & 10 & 12 & \multirow[b]{2}{*}{0.793} \\
\hline$\geq 50$ & 21 & 20 & \\
\hline \multicolumn{4}{|l|}{ Histologic type } \\
\hline SCC & 16 & 21 & \multirow{2}{*}{0.311} \\
\hline $\mathrm{AD} / \mathrm{ASC}$ & 15 & 11 & \\
\hline \multicolumn{4}{|l|}{ FIGO stage } \\
\hline Ib-IIa & 19 & 11 & \multirow{2}{*}{$0.045^{*}$} \\
\hline IIb IIIa & 12 & 21 & \\
\hline \multicolumn{4}{|l|}{ Large Tumor Size } \\
\hline$<4$ & 19 & 12 & \multirow{2}{*}{0.079} \\
\hline$\geq 4$ & 12 & 20 & \\
\hline \multicolumn{4}{|c|}{ Poor Differentiation } \\
\hline Well+Moderate & 23 & 16 & \multirow{2}{*}{0.070} \\
\hline Poor & 8 & 16 & \\
\hline \multicolumn{4}{|c|}{ Lymph node metastasis } \\
\hline Negative & 26 & 9 & \multirow{2}{*}{$<0.001^{* *}$} \\
\hline Positive & 5 & 23 & \\
\hline
\end{tabular}

Low/high by the sample mean. Pearson $\chi^{2}$ test. ${ }^{*} \mathrm{p}<0.05$ was considered statistically significant.
Silenced CRNDE impaired cell proliferation and induced apoptosis in cervical cancer. We conducted cell cytoplasm/nucleus fraction isolation to assess if CRNDE regulated the biological activities of $\mathrm{CC}$ at post-transcriptional level, and found that CRNDE was located in the CC cell cytoplasm (Figure 3A). To better understand the effect

Table 2. Multivariate and univariate analyses of prognostic parameters in patients with cervical cancer by Cox regression analysis.

\begin{tabular}{|c|c|c|c|c|c|c|}
\hline \multirow{3}{*}{ Variable } & \multicolumn{3}{|c|}{ Multivariate analysis } & \multicolumn{3}{|c|}{ Univariate analysis } \\
\hline & \multirow[b]{2}{*}{ p-value } & \multicolumn{2}{|c|}{$95 \% \mathrm{CI}$} & \multirow[b]{2}{*}{ p-value } & \multicolumn{2}{|c|}{$95 \% \mathrm{CI}$} \\
\hline & & Low & High & & Low & High \\
\hline \multicolumn{7}{|l|}{ Age } \\
\hline$<50$ & 0.808 & 0.491 & 1.741 & 0.926 & 0.544 & 1.729 \\
\hline$\geq 50$ & & & & & & \\
\hline \multicolumn{7}{|c|}{ Histologic type } \\
\hline $\begin{array}{l}\mathrm{SCC} \\
\mathrm{AD} / \mathrm{ASC}\end{array}$ & 0.222 & 0.349 & 1.277 & 0.12 & 0.36 & 1.124 \\
\hline \multicolumn{7}{|l|}{ FIGO stage } \\
\hline $\begin{array}{l}\text { Ib-IIa } \\
\text { IIb IIIa }\end{array}$ & 0.761 & 0.569 & 2.161 & 0.365 & 0.744 & 2.231 \\
\hline \multicolumn{7}{|c|}{ Tumor Size (cm) } \\
\hline $\begin{array}{l}<4 \\
\geq 4\end{array}$ & 0.449 & 0.691 & 2.302 & 0.356 & 0.749 & 2.232 \\
\hline \multicolumn{7}{|c|}{ Poor Differentiation } \\
\hline $\begin{array}{l}\text { Moderate } \\
\text { Poor }\end{array}$ & 0.127 & 0.272 & 1.176 & 0.645 & 0.651 & 2.000 \\
\hline \multicolumn{7}{|c|}{ Lymph node metastasis } \\
\hline $\begin{array}{l}\text { Negative } \\
\text { Positive }\end{array}$ & 0.013 & 1.244 & 6.140 & 0.003 & 1.341 & 4.054 \\
\hline \multicolumn{7}{|c|}{ CRNDE level } \\
\hline $\begin{array}{l}\text { High } \\
\text { Low }\end{array}$ & $0.036^{* *}$ & 0.263 & 0.957 & $0.002^{* *}$ & 0.230 & 0.707 \\
\hline
\end{tabular}

Cox regression analysis showed a positive, independent prognostic importance of CRNDE expression $\left(\mathrm{p}=0.036^{*}, \mathrm{p}=0.002^{* *}\right)$. ${ }^{*} \mathrm{p}<0.05$ was considered statistically significant.

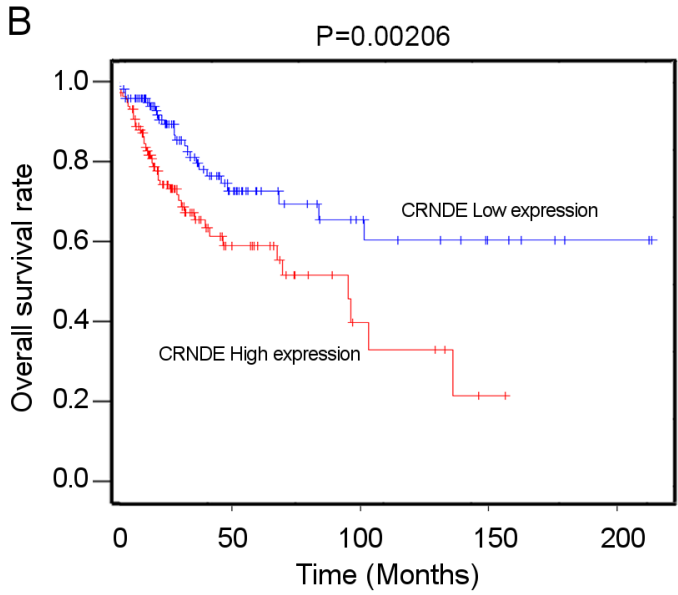

Figure 2. The relevance between CRNDE expression and overall survival for cervical cancer patients (A) was analyzed by means of Kaplan-Meier method analysis and TCGA database analysis $(B)$. Error bars represent means \pm SD from at least three independent experiments were shown. ${ }^{\star *}$ p $<0.01$. 


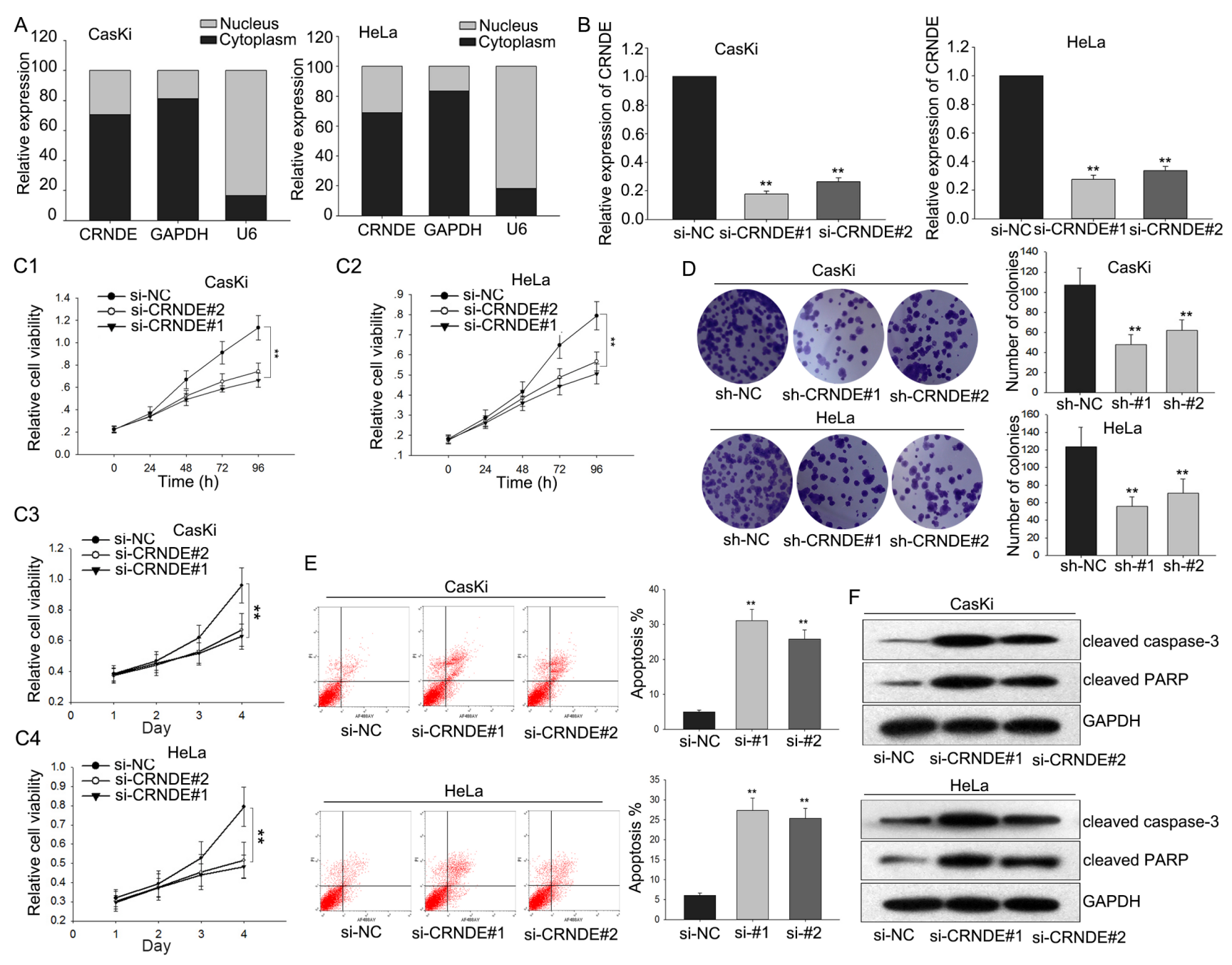

Figure 3. Silenced CRNDE impaired cell proliferation ability and induced apoptosis in cervical cancer. A) We tested the expression of CRNDE in cytoplasm or nucleus in CC cells. GAPDH and U6 were separately used as cytoplasmic marker and nuclear marker. B) Si-CRNDE transfection was performed in CaSki and HeLa cells. C) MTT assay and CCK-8 assay measured the influence of down-regulated CRNDE on the proliferation ability of two CC cells. D) The proliferation ability of CC cells was detected by colony formation assay after sh-CRNDE transfection. E) The effect of down-regulated CRNDE on the apoptosis of CaSki and HeLa cells was analyzed by flow cytometric analysis. F) Western blot assay was applied to examine the expressions of apoptosis-related proteins in response to silenced CRNDE. Error bars represent means \pm SD from at least three independent experiments were shown. ${ }^{* *} \mathrm{p}<0.01$.

of CRNDE on CC cells, we designed loss-of-function assays. Following transfection with siRNA, qRT-PCR analysis showed that CRNDE was observably down-regulated in both CaSki and HeLa cells compared to the si-NC group (Figure 3B). Results of MTT assay and CCK-8 assay revealed that decreased expression of CRNDE suppressed cell viability in the CaSki and HeLa cells (Figure 3C). Similarly, colony formation assay demonstrated the inhibitory effect of silenced CRNDE on cell proliferation ability (Figure 3D) and flow cytometry analysis established increased apoptosis rate in CRNDE-silenced CC cells (Figure 3E). Moreover, the levels of proteins related to apoptosis (cleaved caspase-3 and cleaved PARP) were also increased when CRNDE was silenced (Figure 3F). These combined results suggest that CRNDE acts as a tumor promoter in cell proliferation and inhibits cell apoptosis in cervical cancer.

Knockdown of CRNDE inactivated the PI3K/AKT pathway in cervical cancer. The PI3K/AKT pathway had been identified to be deregulated in tumorigenesis, therefore we hypothesized that the PI3K/AKT pathway participates in CRNDE-mediated biological regulation in CC cells. To prove this, we applied western blot analysis to measure the levels of phosphorylated PI3K (p-PI3K), and AKT (p-AKT) in two CC cells in response to silenced CRNDE. As shown in Figure 4A, silenced CRNDE reduced p-PI3K and p-AKT levels in HeLa cells. We therefore concluded that the PI3K/ 
AKT pathway is involved in CRNDE-mediated function in cervical cancer cells.

CENDE promoted CC proliferation and inhibited apoptosis by targeting PI3K/AKT. We designed and performed rescue assays in HeLa cells to demonstrate the positive influence of CRNDE on CC progression. This revealed that CRNDE was up-regulated in HeLa cells (Figure 5A), so we then measured cell proliferation in the CRNDE-over-expressed CC cells by MTT, CCK-8 and colony formation assays (Figures 5B-D). The results showed that over-expression of CRNDE inhibited cell apoptosis.

LY94002 is an effective inhibitor of the PI3K-AKT signaling pathway [21]. We added this to the CRNDE-upregulated HeLa cells and the inactivated PI3K-AKT signaling pathway reversed the increased cell proliferation. Our flow cytometry and Western blot analyses then detected cell apoptosis (Figures 5E-F), and results confirmed that the decreased apoptotic rate of CRNDE-over-expressed HeLa cells is enhanced by LY94002 supplement. The combined results enabled the conclusion that CRNDE promotes cell proliferation and suppresses cell apoptosis in cervical cancer through modulation of the PI3K-AKT signaling pathway.

\section{Discussion}

It has been revealed that almost $97 \%$ of the human genome sequence is transcribed into non-coding RNAs (ncRNAs), and long noncoding RNAs (lncRNAs) are proposed as valuable novel molecules because they are deregulated in many cancers $[8,22-24]$. For example, Zhang $\mathrm{R}$ et al. certified that lncRNA TP73-AS1 interacts with miR-142, thus modulating cell growth in brain glioma by activating the HMGB1/RAGE pathway [17].

Ye K et al. previously proved that lncRNA GAS5 negatively affected cell growth and reversed epithelial-mesenchymal transition in osteosarcoma by modulating the miR-221/ ARHI pathway [25]. And Ma F et al. revealed that lncRNA TUG1 accelerated proliferation and metastasis in gallbladder carcinoma cells by negatively manipulating miR-300 [26] .

Many other lncRNAs were also identified to exert critical biological functions in cervical cancer. For example, lncRNA PVT1 epigenetically silences miR-195, thus affecting EMT and chemo-resistance in cervical cancer cells [27]. Further, LncRNA HOXA11 antisense motivates the progression and maintenance of stem cells in cervical cancer [28], and
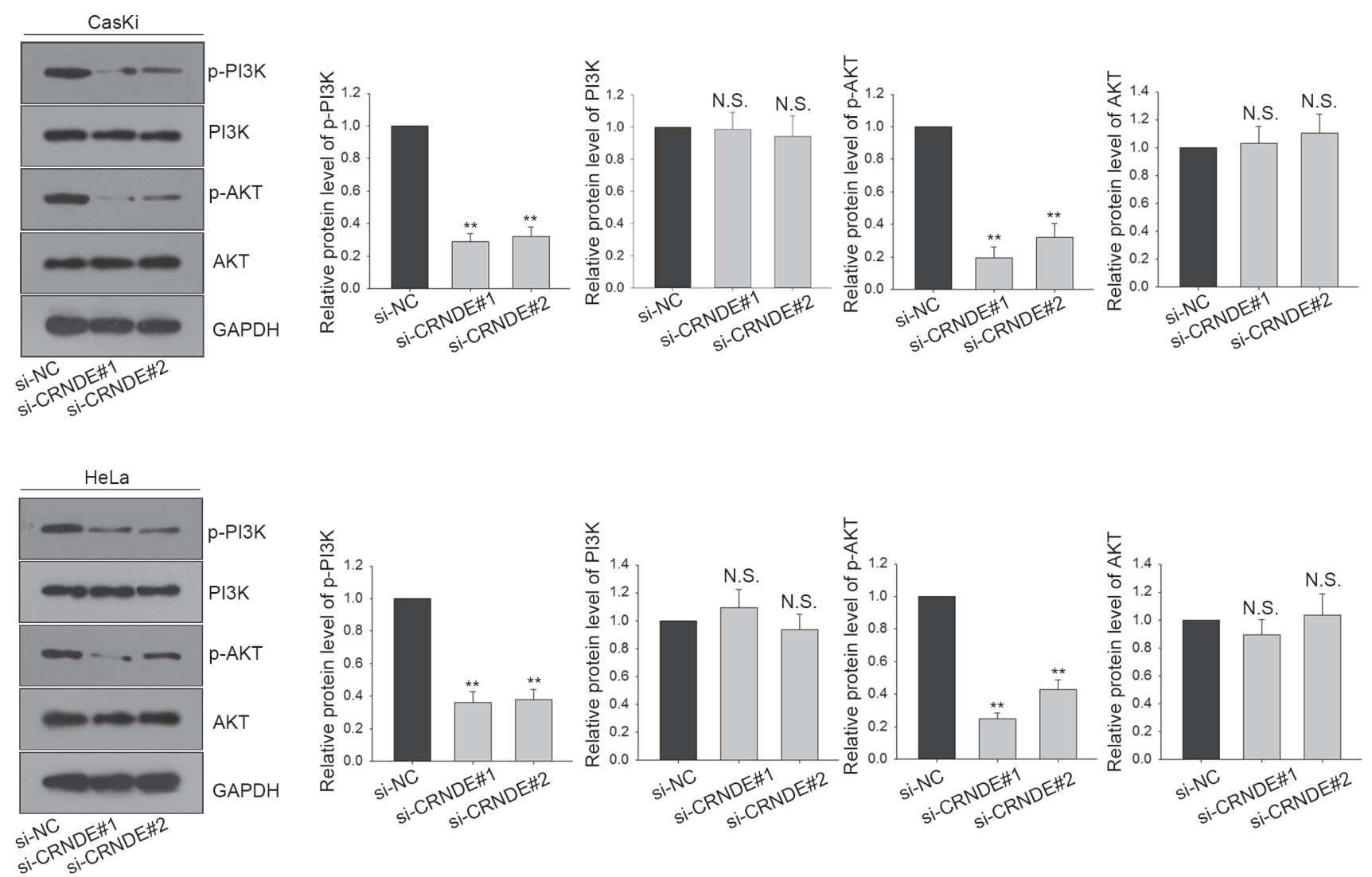

Figure 4. Knockdown of CRNDE inactivated the PI3K/AKT pathway in cervical cancer. Western blot assay was conducted to measure the levels of p-PI3K, PI3K, p-AKT and AKT in two CC cells in response to silenced CRNDE. Error bars represent means \pm SD from at least three independent experiments were shown. ${ }^{* *} \mathrm{p}<0.01$. 

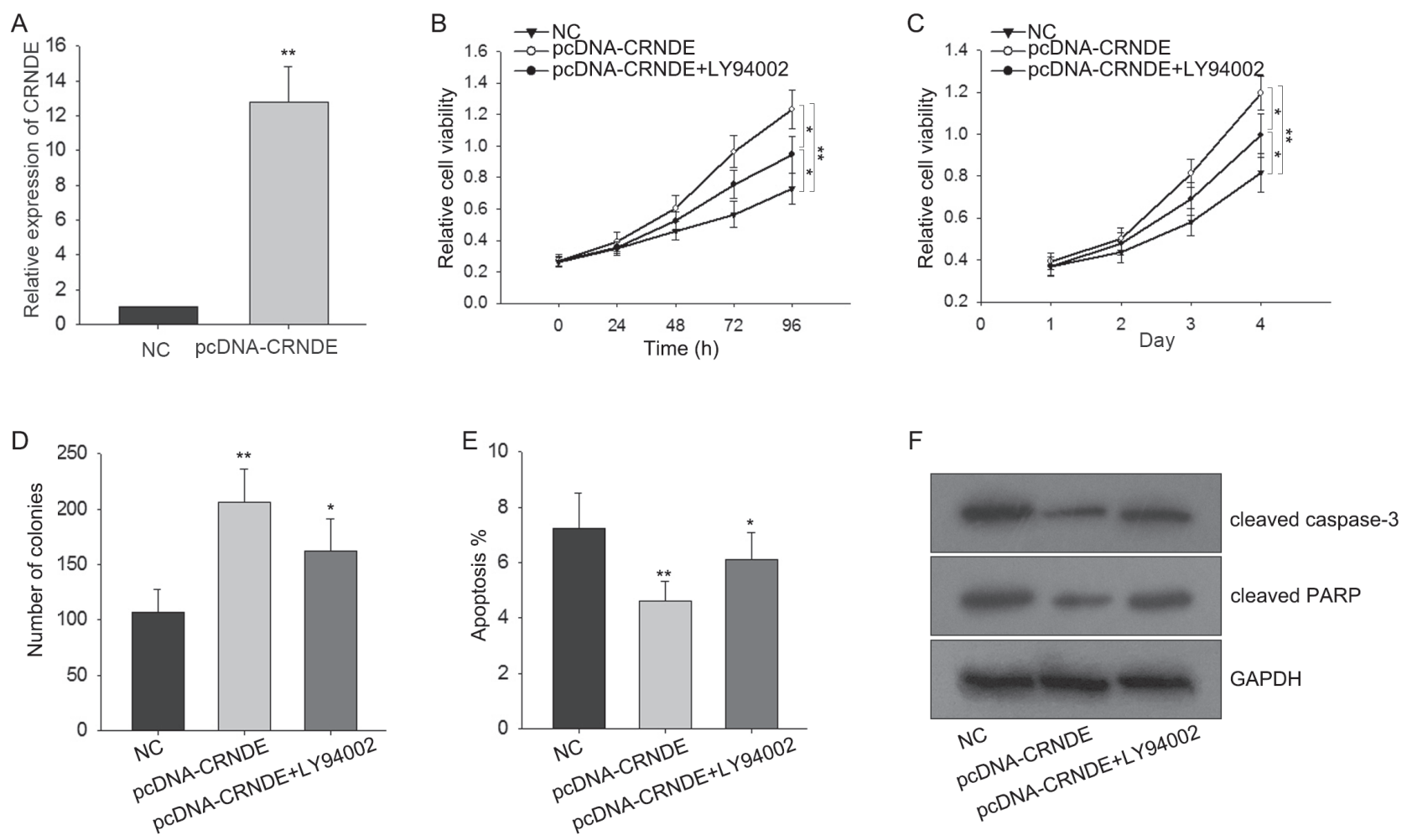

Figure 5. CENDE promoting proliferation and inhibiting apoptosis of cervical cancer cells through targeting PI3K/AKT. A) CRNDE was upregulated in HeLa cells by transfection of pcDNA-CRNDE. Cell proliferation was examined by MTT (B), CCK-8 (C) and colony formation assays (D) after HeLa cell was co-transfected with pcDNA-CRNDE and LY94002. E) Flow cytometry analysis investigated the influence of pcDNA-CRNDE and LY94002 on HeLa cell apoptosis. F) The apoptosis condition of HeLa cell was measured by western blot analysis through measuring the apoptotic proteins. Error bars represent means \pm SD from at least three independent experiments were shown. ${ }^{* *} \mathrm{p}<0.01$.

lncRNA ANRIL forecasts poor prognosis of cervical cancer and further stimulates carcinogenesis through the PI3K/ AKT pathways [29]. Despite this research, there are still many unknown lncRNAs requiring investigation.

LncRNA Colorectal Neoplasia Differentially Expressed (CRNDE), which was transcribed from chromosome 16 on the strand opposite to the contiguous IRX5 gene, was originally found up-regulated in CRC and then reported to be abnormally expressed in many other cancers $[10,12,16,30]$. However, its potential role and molecular mechanisms in cervical cancer remain unclear. In addition to all of the above reports, CRNDE can act as an oncogene to affect EMT formation, cell growth, metastasis and other processes through interaction with the PI3K/AKT signaling pathway. For example, CRNDE exerts oncogenic function in gallbladder carcinoma through the PI3K/AKT signaling pathway [15], and therefore it is proposed that CRNDE can interact with this pathway to promote cancer progression.

Herein, we demonstrated that CRNDE was significantly up-regulated in CC tissues and cells, and its increased expression is obviously associated with FIGO stages, lymph node metastasis and closely correlated with poor prognosis in cervical cancer patients. Loss-of-function assays then demonstrated that CRNDE knockdown significantly inhib- ited CC cell proliferation and increased their apoptosis. Further mechanism experiments revealed that PI3K/AKT is involved in CRNDE-mediated CC function, and our next study will focus on the mechanism of CRNDE mechanisms in regulating cervical cancer cells.

In conclusion, we demonstrated that CRNDE was certainly up-regulated in cervical cancer cell lines and tissues and was closely correlated with poor prognosis in cervical cancer patients. The cellular assays proved that CRNDE participates in multiple CC processes, and the combined results imply that CRNDE should be a successful candidate as both a prognostic biomarker and target in cervical cancer treatment.

Supplementary information is available in the online version of the paper.

Acknowledgments: The authors thank the laboratory members.

\section{References}

[1] ZHANG CL, ZHU KP, MA XL. Antisense lncRNA FOXC2AS1 promotes doxorubicin resistance in osteosarcoma by increasing the expression of FOXC2. Cancer Lett 2017. 396: 66-75. https://doi.org/10.1016/j.canlet.2017.03.018 
[2] YU H, XUE Y, WANG P, LIU X, MA J et al. Knockdown of long non-coding RNA XIST increases blood-tumor barrier permeability and inhibits glioma angiogenesis by targeting miR-137. Oncogenesis 2017; 6: e303. https://doi. org/10.1038/oncsis.2017.7

[3] YANG R, LI P, ZHANG G, LU C, WANG H et al. Long NonCoding RNA XLOC_008466 Functions as an Oncogene in Human Non-Small Cell Lung Cancer by Targeting miR874. Cell Physiol Biochem 2017; 42: 126-136. https://doi. org/10.1159/000477121

[4] XUE Y, NI T, JIANG Y, LI Y. Long Noncoding RNA GAS5 Inhibits Tumorigenesis and Enhances Radiosensitivity By Suppressing miR-135b Expression in Non-Small Cell Lung Cancer. Oncol Res 2017; 25: 1305-1316. https://doi.org/10.3 727/096504017X14850182723737

[5] XU J, ZHANG R, ZHAO J. The Novel Long Noncoding RNA TUSC7 Inhibits Proliferation by Sponging MiR-211 in Colorectal Cancer. Cell Physiol Biochem 2017; 41: 635-644. https://doi.org/10.1159/000457938

[6] XIONG H, NI Z, HE J, JIANG S, LI X et al. LncRNA HULC triggers autophagy via stabilizing Sirt1 and attenuates the chemosensitivity of HCC cells. Oncogene 2017; 36: 35283540. https://doi.org/10.1038/onc.2016.521

[7] XIAO JN, YAN TH, YU RM, GAO Y, ZENG WL et al. Long non-coding RNA UCA1 regulates the expression of Snail2 by miR-203 to promote hepatocellular carcinoma progression. J Cancer Res Clin Oncol 2017;143: 981-990. https:// doi.org/10.1007/s00432-017-2370-1

[8] XIA M, YAO L, ZHANG Q, WANG F, MEI H et al. Long noncoding RNA HOTAIR promotes metastasis of renal cell carcinoma by up-regulating histone H3K27 demethylase JMJD3. Oncotarget 2017; 8: 19795-19802. https://doi. org/10.18632/oncotarget.15047

[9] LIU T, ZHANG X, YANG YM, DU LT, WANG CX. Increased expression of the long noncoding RNA CRNDE-h indicates a poor prognosis in colorectal cancer, and is positively correlated with IRX5 mRNA expression. Onco Targets Ther 2016; 9: 1437-1448. https://doi.org/10.2147/OTT. S98268

[10] GRAHAM LD, PEDERSEN SK, BROWN GS, HO T, KASSIR Z et al. Colorectal Neoplasia Differentially Expressed (CRNDE), a Novel Gene with Elevated Expression in Colorectal Adenomas and Adenocarcinomas. Genes Cancer 2011; 2: 829-840. https://doi.org/10.1177/1947601911431081

[11] CHEN Z, YU C, ZHAN L, PAN Y, CHEN L et al. LncRNA CRNDE promotes hepatic carcinoma cell proliferation, migration and invasion by suppressing miR-384. Am J Cancer Res 2016; 6: 2299-2309.

[12] DONG R, LIU XQ, ZHANG BB, LIU BH, ZHENG S et al. Long non-coding RNA-CRNDE: a novel regulator of tumor growth and angiogenesis in hepatoblastoma. Oncotarget 2017; 8: 42087-42097. https://doi.org/10.18632/oncotarget.14992

[13] JING SY, LU YY, YANG JK, DENG WY, ZHOU Q et al. Expression of long non-coding RNA CRNDE in glioma and its correlation with tumor progression and patient survival. Eur Rev Med Pharmacol Sci 2016; 20: 3992-3996.
[14] SHAO K, SHI T, YANG Y, WANG X, XU D et al. Highly expressed lncRNA CRNDE promotes cell proliferation through Wnt/beta-catenin signaling in renal cell carcinoma. Tumour Biol 2016. https://doi.org/10.1007/s13277-016-5440-0

[15] SHEN S, LIU H, WANG Y, WANG J, NI X et al. Long noncoding RNA CRNDE promotes gallbladder carcinoma carcinogenesis and as a scaffold of DMBT1 and C-IAP1 complexes to activating PI3K-AKT pathway. Oncotarget 2016; 7: 72833-72844. https://doi.org/10.18632/oncotarget.12023

[16] SZAFRON LM, BALCERAK A, GRZYBOWSKA EA, PIENKOWSKA-GRELA B, PODGORSKA A et al. The putative oncogene, CRNDE, is a negative prognostic factor in ovarian cancer patients. Oncotarget 2015; 6: 43897-43910. https://doi.org/10.18632/oncotarget.6016

[17] YIN K, WANG L, ZHANG X, HE Z, XIA Y et al. Netrin-1 promotes gastric cancer cell proliferation and invasion via the receptor neogenin through PI3K/AKT signaling pathway. Oncotarget 2017; 8: 51177-51189. https://doi.org/10.18632/ oncotarget. 17750

[18] YE J, HUANG J, XU J, HUANG Q, WANG J et al. ERp29 controls invasion and metastasis of gastric carcinoma by inhibition of epithelial-mesenchymal transition via PI3K/Aktsignaling pathway. BMC Cancer 2017; 17: 626. https://doi. org/10.1186/s12885-017-3613-x

[19] WANG SC, CHAI DS, CHEN CB, WANG ZY, WANG L. HPIP promotes thyroid cancer cell growth, migration and EMT through activating PI3K/AKT signaling pathway. Biomed Pharmacother 2015; 75: 33-39. https://doi. org/10.1016/j.biopha.2015.08.027

[20] JUNG W, PARK KR, LEE KJ, KIM K, LEE J et al. Value of imaging study in predicting pelvic lymph node metastases of uterine cervical cancer. Radiat Oncol J 2017; 35: 340-348. https://doi.org/10.3857/roj.2017.00206

[21] FENG Y, ZU LL, ZHANG L. MicroRNA-26b inhibits the tumor growth of human liver cancer through the PI3K/Akt and NF-kappaB/MMP-9/VEGF pathways. Oncol Rep 2018; 39: 2288-2296. https://doi.org/10.3892/or.2018.6289

[22] ZHU M, LIU J, XIAO J, YANG L, CAI M et al. Lnc-mg is a long non-coding RNA that promotes myogenesis. Nat Commun 2017; 8: 14718. https://doi.org/10.1038/ncomms14718

[23] ZHANG CZ. Long non-coding RNA FTH1P3 facilitates oral squamous cell carcinoma progression by acting as a molecular sponge of miR-224-5p to modulate fizzled 5 expression. Gene 2017; 607: 47-55. https://doi.org/10.1016/j. gene.2017.01.009

[24] XIA S, JI R, ZHAN W. Long noncoding RNA papillary thyroid carcinoma susceptibility candidate 3 (PTCSC3) inhibits proliferation and invasion of glioma cells by suppressing the Wnt/beta-catenin signaling pathway. BMC Neurol 2017; 17: 30. https://doi.org/10.1186/s12883-017-0813-6

[25] YE K, WANG S, ZHANG H, HAN H, MA B et al. Long noncoding RNA GAS5 suppresses cell growth and epithelialmesenchymal transition in osteosarcoma by regulating the miR-221/ARHI pathway. J Cell Biochem 2017; 118: 47724781. https://doi.org/10.1002/jcb.26145 
[26] MA F, WANG SH, CAI Q, JIN LY, ZHOU D et al. Long noncoding RNA TUG1 promotes cell proliferation and metastasis by negatively regulating miR-300 in gallbladder carcinoma. Biomed Pharmacother 2017; 88: 863-869. https://doi. org/10.1016/j.biopha.2017.01.150

[27] SHEN CJ, CHENG YM, WANG CL. LncRNA PVT1 epigenetically silences miR-195 and modulates EMT and chemoresistance in cervical cancer cells. J Drug Target 2017; 25: 637-644. https://doi.org/10.1080/1061186X.2017.1307379

[28] KIM HJ, EOH KJ, KIM LK, NAM EJ, YOON SO et al. The long noncoding RNA HOXA11 antisense induces tumor progression and stemness maintenance in cervical cancer. Oncotarget 2016; 7: 83001-83016. https://doi.org/10.18632/ oncotarget.12863
[29] ZHANG D, SUN G, ZHANG H, TIAN J, LI Y. Long noncoding RNA ANRIL indicates a poor prognosis of cervical cancer and promotes carcinogenesis via PI3K/Akt pathways. Biomed Pharmacother 2017; 85: 511-516. https://doi. org/10.1016/j.biopha.2016.11.058

[30] LIU T, ZHANG X, GAO S, JING F, YANG Y et al. Exosomal long noncoding RNA CRNDE-h as a novel serum-based biomarker for diagnosis and prognosis of colorectal cancer. Oncotarget 2016; 7: 85551-85563. https://doi.org/10.18632/ oncotarget. 13465 


\section{CRNDE}

\begin{tabular}{|c|c|}
\hline normal & 107,3966786 \\
\hline normal & 160,5443433 \\
\hline normal & 161,5507771 \\
\hline tumor & 74,21251916 \\
\hline tumor & 1103,872679 \\
\hline tumor & 1011,889115 \\
\hline tumor & 273,4128674 \\
\hline tumor & 633,8547494 \\
\hline tumor & 27,62760588 \\
\hline tumor & 67,37949853 \\
\hline tumor & 1006,339849 \\
\hline tumor & 1334,155171 \\
\hline tumor & 905,0847685 \\
\hline tumor & 424,5145913 \\
\hline tumor & 556,1034845 \\
\hline tumor & 1256,404795 \\
\hline tumor & 286,987434 \\
\hline tumor & 1633,030507 \\
\hline tumor & 32,61966104 \\
\hline tumor & 338,0057515 \\
\hline tumor & 717,4761551 \\
\hline tumor & 936,2793411 \\
\hline tumor & 437,570312 \\
\hline tumor & 220,8428426 \\
\hline tumor & 125,2022562 \\
\hline tumor & 903,6390586 \\
\hline tumor & 1339,344532 \\
\hline tumor & 1503,843881 \\
\hline tumor & 335,3098486 \\
\hline tumor & 600,8249719 \\
\hline tumor & 1107,700388 \\
\hline tumor & 1580,927796 \\
\hline tumor & 651,0630041 \\
\hline tumor & 858,1838364 \\
\hline tumor & 916,4337815 \\
\hline tumor & 730,1981488 \\
\hline tumor & 901,2548198 \\
\hline tumor & 903,5455715 \\
\hline tumor & 1885,20465 \\
\hline tumor & 666,7984009 \\
\hline tumor & 580,5147026 \\
\hline tumor & 712,428023 \\
\hline tumor & 1115,539848 \\
\hline tumor & 856,9020562 \\
\hline tumor & 339,7658332 \\
\hline tumor & 713,4074851 \\
\hline umor & 282,3537049 \\
\hline tumor & 2100,033774 \\
\hline tumor & 134,9976078 \\
\hline
\end{tabular}




\begin{tabular}{|c|c|}
\hline tumor & 422,8103515 \\
\hline tumor & 804,1729719 \\
\hline tumor & 2,933325676 \\
\hline tumor & 1137,561811 \\
\hline tumor & 784,9123571 \\
\hline tumor & 1310,202068 \\
\hline tumor & 657,4030021 \\
\hline tumor & 584,5390423 \\
\hline tumor & 762,4199259 \\
\hline tumor & 200,1889723 \\
\hline tumor & 1389,082711 \\
\hline tumor & 984,907891 \\
\hline tumor & 815,8202835 \\
\hline tumor & 482,2119158 \\
\hline tumor & 814,9838996 \\
\hline tumor & 1299,072346 \\
\hline tumor & 1246,807091 \\
\hline tumor & 1332,133632 \\
\hline tumor & 1406,395742 \\
\hline tumor & 2595,449006 \\
\hline tumor & 862,6000683 \\
\hline tumor & 1298,5035 \\
\hline tumor & 1252,273436 \\
\hline tumor & 839,8818538 \\
\hline tumor & 1068,45658 \\
\hline tumor & 1727,642396 \\
\hline tumor & 685,3366676 \\
\hline tumor & 1046,699947 \\
\hline tumor & 1706,271909 \\
\hline tumor & 1111,863151 \\
\hline tumor & 697,0816905 \\
\hline tumor & 662,4148369 \\
\hline tumor & 819,7991427 \\
\hline tumor & 831,2758036 \\
\hline tumor & 1253,434546 \\
\hline tumor & 608,4631462 \\
\hline tumor & 1322,678413 \\
\hline tumor & 1643,910343 \\
\hline tumor & 556,7594853 \\
\hline tumor & 1484,133473 \\
\hline tumor & 1209,478385 \\
\hline tumor & 873,4436749 \\
\hline tumor & 490,5945446 \\
\hline tumor & 2102,550988 \\
\hline tumor & 1051,097968 \\
\hline tumor & 1089,676009 \\
\hline tumor & 799,6373606 \\
\hline tumor & 29,43186664 \\
\hline tumor & 417,3420315 \\
\hline tumor & 769,6261582 \\
\hline
\end{tabular}




\begin{tabular}{|c|c|}
\hline tumor & 1000,738377 \\
\hline tumor & 876,5064481 \\
\hline tumor & 570,1899267 \\
\hline tumor & 1247,849932 \\
\hline tumor & 27,17217877 \\
\hline tumor & 1161,42568 \\
\hline tumor & 2054,829891 \\
\hline tumor & 600,8102399 \\
\hline tumor & 2149,730912 \\
\hline tumor & 1039,024806 \\
\hline tumor & 1239,782994 \\
\hline tumor & 1029,194542 \\
\hline tumor & 1250,110926 \\
\hline tumor & 1155,985003 \\
\hline tumor & 707,9484532 \\
\hline tumor & 1112,537274 \\
\hline tumor & 1333,849861 \\
\hline tumor & 361,3147581 \\
\hline tumor & 858,2672973 \\
\hline tumor & 562,7245282 \\
\hline tumor & 70,50874102 \\
\hline tumor & 2611,519783 \\
\hline tumor & 1107,779478 \\
\hline tumor & 1034,340728 \\
\hline tumor & 1261,549082 \\
\hline tumor & 2591,551963 \\
\hline tumor & 560,9691816 \\
\hline tumor & 1851,53898 \\
\hline tumor & 1037,921644 \\
\hline tumor & 924,3960218 \\
\hline tumor & 676,128036 \\
\hline tumor & 1629,340036 \\
\hline tumor & 394,2056602 \\
\hline tumor & 797,3012899 \\
\hline tumor & 1952,369816 \\
\hline tumor & 1495,762579 \\
\hline tumor & 729,9364738 \\
\hline tumor & 948,3045826 \\
\hline tumor & 165,1500582 \\
\hline tumor & 846,0996579 \\
\hline tumor & 1386,657683 \\
\hline tumor & 1273,729843 \\
\hline tumor & 1096,699982 \\
\hline tumor & 582,0346558 \\
\hline tumor & 1363,595817 \\
\hline tumor & 1418,220624 \\
\hline tumor & 1030,422016 \\
\hline tumor & 1097,89899 \\
\hline tumor & 803,6144412 \\
\hline tumor & 262,2814846 \\
\hline
\end{tabular}




\begin{tabular}{|c|c|}
\hline tumor & 578,324303 \\
\hline tumor & 1155,781429 \\
\hline tumor & 194,0490131 \\
\hline tumor & 1192,678497 \\
\hline tumor & 670,261168 \\
\hline tumor & 2514,728645 \\
\hline tumor & 603,3536821 \\
\hline tumor & 1244,878199 \\
\hline tumor & 1142,00311 \\
\hline tumor & 824,3419256 \\
\hline tumor & 1241,031542 \\
\hline tumor & 689,0241921 \\
\hline tumor & 390,0235501 \\
\hline tumor & 134,7739204 \\
\hline tumor & 590,1310007 \\
\hline tumor & 1551,019516 \\
\hline tumor & 634,0370066 \\
\hline tumor & 872,5563642 \\
\hline tumor & 1731,11503 \\
\hline tumor & 1181,477643 \\
\hline tumor & 1291,305471 \\
\hline tumor & 1849,344088 \\
\hline tumor & 1429,217344 \\
\hline tumor & 1691,025765 \\
\hline tumor & 1240,161176 \\
\hline tumor & 1013,29742 \\
\hline tumor & 932,8857983 \\
\hline tumor & 688,7656288 \\
\hline tumor & 1451,557458 \\
\hline tumor & 24,47670872 \\
\hline tumor & 1544,284767 \\
\hline tumor & 449,7124578 \\
\hline tumor & 996,315827 \\
\hline tumor & 1000,812201 \\
\hline tumor & 933,7271427 \\
\hline tumor & 2716,12742 \\
\hline tumor & 793,3377868 \\
\hline tumor & 2085,82028 \\
\hline tumor & 938,8864299 \\
\hline tumor & 846,3244644 \\
\hline tumor & 450,0697891 \\
\hline tumor & 1138,822134 \\
\hline tumor & 2337,051949 \\
\hline tumor & 440,4575728 \\
\hline tumor & 859,6111084 \\
\hline tumor & 1626,469825 \\
\hline tumor & 585,0776367 \\
\hline tumor & 214,5610955 \\
\hline tumor & 1414,661706 \\
\hline tumor & 1311,99436 \\
\hline
\end{tabular}




\begin{tabular}{|c|c|}
\hline tumor & 1928,787657 \\
\hline tumor & 1220,974582 \\
\hline tumor & 1771,608287 \\
\hline tumor & 350,9967748 \\
\hline tumor & 641,486963 \\
\hline tumor & 1337,858899 \\
\hline tumor & 1878,315636 \\
\hline tumor & 760,7703439 \\
\hline tumor & 261,5593467 \\
\hline tumor & 1396,464207 \\
\hline tumor & 920,4159117 \\
\hline tumor & 762,3211634 \\
\hline tumor & 47,13945615 \\
\hline tumor & 1005,033158 \\
\hline tumor & 32,19749126 \\
\hline tumor & 2047,979556 \\
\hline tumor & 763,4831701 \\
\hline tumor & 1266,999859 \\
\hline tumor & 1548,370781 \\
\hline tumor & 1210,944218 \\
\hline tumor & 42,12259575 \\
\hline tumor & 1364,603265 \\
\hline tumor & 956,7745198 \\
\hline tumor & 875,7062213 \\
\hline tumor & 1775,980367 \\
\hline tumor & 1436,018317 \\
\hline tumor & 2220,353086 \\
\hline tumor & 1004,47182 \\
\hline tumor & 933,3757914 \\
\hline tumor & 1269,806728 \\
\hline tumor & 885,6855516 \\
\hline tumor & 889,5422033 \\
\hline tumor & 770,5243014 \\
\hline tumor & 1876,535845 \\
\hline tumor & 548,409031 \\
\hline tumor & 1335,45377 \\
\hline tumor & 2043,45523 \\
\hline tumor & 3534,867224 \\
\hline tumor & 72,45099307 \\
\hline tumor & 1192,003792 \\
\hline tumor & 929,891154 \\
\hline tumor & 1730,920381 \\
\hline tumor & 445,2256016 \\
\hline tumor & 1182,137805 \\
\hline tumor & 334,9441485 \\
\hline tumor & 567,381588 \\
\hline tumor & 1053,047768 \\
\hline tumor & 2065,003506 \\
\hline tumor & 763,4878508 \\
\hline tumor & 1410,024634 \\
\hline
\end{tabular}




\begin{tabular}{|c|c|}
\hline tumor & 797,989319 \\
\hline tumor & 698,4418976 \\
\hline tumor & 929,8511135 \\
\hline tumor & 362,0700608 \\
\hline tumor & 687,9834998 \\
\hline tumor & 1297,954502 \\
\hline tumor & 855,5663002 \\
\hline tumor & 473,9689051 \\
\hline tumor & 1193,162547 \\
\hline tumor & 1062,265062 \\
\hline tumor & 495,2289142 \\
\hline tumor & 1045,516939 \\
\hline tumor & 850,5483294 \\
\hline tumor & 1065,010754 \\
\hline tumor & 1042,782686 \\
\hline tumor & 1996,295655 \\
\hline tumor & 1778,393541 \\
\hline tumor & 243,4249964 \\
\hline tumor & 1994,110271 \\
\hline tumor & 50,98234898 \\
\hline tumor & 3566,922106 \\
\hline tumor & 300,0431203 \\
\hline tumor & 2071,429442 \\
\hline tumor & 1682,365009 \\
\hline tumor & 832,2537988 \\
\hline tumor & 657,9734344 \\
\hline tumor & 1388,824591 \\
\hline tumor & 740,6674298 \\
\hline tumor & 973,549192 \\
\hline tumor & 704,4505619 \\
\hline tumor & 441,5509903 \\
\hline tumor & 1352,716672 \\
\hline tumor & 1246,432737 \\
\hline tumor & 750,7599559 \\
\hline tumor & 1274,404138 \\
\hline tumor & 646,8105132 \\
\hline tumor & 1561,239866 \\
\hline tumor & 1301,821871 \\
\hline tumor & 2206,893389 \\
\hline tumor & 689,7151061 \\
\hline tumor & 521,9085891 \\
\hline tumor & 480,3217841 \\
\hline tumor & 304,1867999 \\
\hline tumor & 715,4286406 \\
\hline tumor & 1045,644278 \\
\hline tumor & 1389,647075 \\
\hline tumor & 1081,75478 \\
\hline tumor & 1004,116347 \\
\hline tumor & 1170,906145 \\
\hline tumor & 2241,957675 \\
\hline
\end{tabular}



tumor
1115,625889
tumor $\quad 352,6922191$
tumor $\quad 741,4827554$
tumor $\quad 252,3728166$
tumor $\quad 781,1592475$
tumor 1208,313628
tumor 2038,086377
tumor $\quad 1486,106806$
tumor $\quad 915,3334469$
tumor 1365,440341 